\title{
Acute Total Uterine Inversion: A Life Threatening Obstetric Emergency
}

\author{
Shrestha $\mathbf{R}^{1}$, Shrestha SD ${ }^{1}$, Malla AP ${ }^{1}$, Pradhan $\mathbf{R}^{1}$, Pradhan $\mathbf{B}^{1}, \mathbf{R C} \mathbf{L}^{1}$ \\ ${ }^{1}$ Department of Obstetrics and Gynecology Patan Academy of Health Science, Lalitpur, Nepal
}

Received: 22-Feb-2017; Accepted: 20-May-2017

Acute total uterine inversion is a rare and life threatening obstetric emergency. Prompt diagnosis and aggressive managemen reduces maternal mortality and morbidity. We report a case of 28 year old primi, who had total uterine inversion immediately after normal delivery of full term baby weighing $3150 \mathrm{gm}$. Immediate manual repositioning was done by Johnson's maneuver under general anesthesia. She recovered well and was discharged after 5 days.

Keywords: Johnson's maneuver, uterine inversion

DOI: http://dx.doi.org/10.3126/njog.v12i1.18987

\section{INTRODUCTION}

Uterine inversion is a rare and life threatening complication of vaginal delivery. Incidence varies considerably ranging from 1 in 550 to 1 in 50,000 vaginal deliveries. ${ }^{1}$ Maternal mortality as high as 15 $\%$ has been reported. ${ }^{2,3}$ Early diagnosis and prompt management of uterine inversion is essential for reducing maternal mortality and morbidity. Here we report a case of 28 year old primi with acute total uterine inversion immediately after vaginal delivery which was managed successfully with manual reposition of uterus.

\section{CASE}

A 28 year old primi, with previous normal antenatal checkup (ANC), presented to maternity ward in labor pain at 40 weeks of gestation. There was normal progression of labor and she delivered a female baby weighing 3150 gram with 9/10 Apgar score by vaginal delivery with episiotomy. Soon after delivery fleshy mass protruded out of vagina with placenta attached to it (Fig.1).Uterus was not palpable per abdomen. Patient was tachycardic and blood pressure dropped to $90 / 60 \mathrm{~mm} \mathrm{hg}$. We made the diagnosis of acute total uterine inversion.Oxytocin infusion was stopped, IV fluids was given through two wide bore cannula. She was immediately shifted to operation theater and under general anesthesia manual reposition of uterus was done by Johnson's maneuver. After successful reposition of uterus, placenta (fundal attachment)

\section{CORRESPONDENCE}

Dr Reena Shrestha

Department of Obstetrics and Gynecology

Patan Academy of Health Science, Lalitpur, Nepal

Phone: +977-9851185925

Email: drreenashrestha@hotmail.com was removed manually. Uterus was flabby so uterine massage was done. Oxytocin infusion started, misoprostol was given per rectally and IV antibiotics given. She was shifted to intensive care unit; her hemoglobin was $8.7 \mathrm{gm} \%$ hence two units of whole blood were transfused. There were no other early postpartum complications. She was discharged on $5^{\text {th }}$ day.

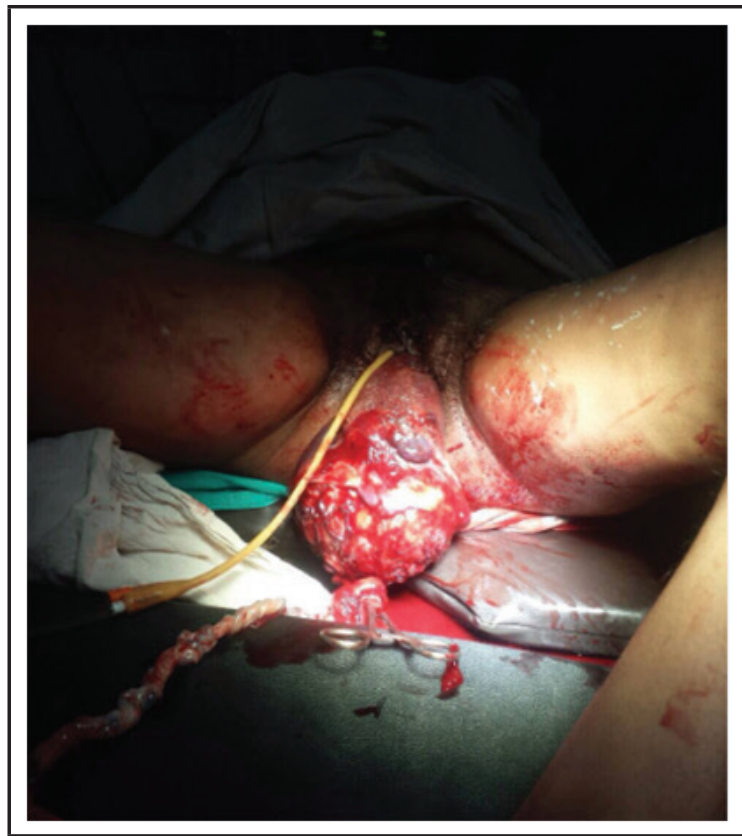

Figure 1. Fleshy mass protruding out of vagina with placenta attached to it

\section{COMMENT}

Uterine inversion is a rare and life threatening complication of vaginal delivery. The reported incidence varies ranging from 1 in 550 to 1 in several thousand deliveries. ${ }^{1}$ Dali et $\mathrm{al}^{2}$ reported 6 cases of puerperal inversion in Nepal in a 20 
years retrospective study (1975 to 1995). Maternal mortality upto $15 \%$ has been reported. ${ }^{1}$ Uterine inversion can be acute,subacute or chronic .The acute inversions occur immediately or within 24 hours; sub-acute inversion occurs after 24 hours to 4 weeks; and chronic inversion occurs after 4 weeks of delivery. ${ }^{3}$ The reported prevalence of acute, subacute and chronic inversion is $83.4 \%, 2.62 \%$ and $13.9 \%$ respectively. ${ }^{4}$

The exact etiology is not known, but mismanagement of the third stage of labor is common cause of uterine inversion. The risk factors for spontaneous uterine inversion are primipara, fundal attachment of placenta, macrosomia, short cord, use of oxytocis. ${ }^{5}$ Primipara and fundal attachment of placenta were the risk factor in our case.

Prompt diagnosis and management is needed as delay can lead to maternal death due to hypovolaemic and neurogenic shock. The treatment consist of antishock therapy and immediate repositioning of uterus manually(Johnson's maneuver) or hydrostatic
reduction(O'Sullivian). In our case we had successful reposition of uterus by Johnson's maneuver under general anaesthesia. Delay will lead to edema and formation of constriction ring preventing repositioning. In such situation surgical methods are utilized like incision of the constriction ring vaginally (Spinelli), upward traction on the round ligaments with the assistant applying upward pressure from the vagina (Huntington) and incising the constriction ring posteriorly at laparotomy (Haultain). ${ }^{6}$ The newer methods include laparoscopic reduction, the use of obstetric ventouse at laparotomy. ${ }^{7,8}$

Removal of placenta should be done only after repositioning of uterus, as it reduces blood loss. ${ }^{9} \mathrm{~A}$ wide spectrum antibiotics should be used to prevent sepsis and endometritis. ${ }^{10}$

\section{CONCLUSIONS}

Acute total uterine inversion is rare but a life threatening complication of third stage of labor. Manual repositioning is successful if it is promptly diagnosed.

\section{REFERENCES}

1. Hostetler DR, Bosworth MF. Uterine inversion: a lifethreatening obstetric emergency. J Am Board Fam Pract. $2000 ; 13(2): 120-3$

2. Dali SM, Rajbhandari S, Shrestha S. Puerperal inversion of the uterus in Nepal: case reports and review of literature. J Obstet Gynaecol Res. 1997;23(3):319-25.

3. Wendel PJ, Cox SM. Emergent Obstetric management of uterine inversion. Obstet Gynecol Clin North Am. $1995 ; 22(2): 261-74$

4. Shah-Hosseini R, Evrard JR. Puerperal uterine inversion. Obstet Gynecol. 1989;73(4):567-70.

5. Witteveen T, Van Stralen G, Zwart J, Van Roosmalen J: Puerperal uterine inversion in the Netherlands: a nationwide cohort study. Acta Obstet Gynecol Scand. 2013;92:334.
6. vanVugt PJH, Baudoin $\mathrm{P}$, Blom $\mathrm{MV}$, vanDeursen STBM. Inveriso uteri puerperalis. Acta Obstet Gynaecol Scand.1981;60:353-6

7. Rajagopalan V, Sujatha Y. Acute postpartum uterine inversion with hemorrhagic shock with laparoscopic reduction: a new method of management. BJOG 2006;113:1100-2.

8. Antonelli E, Irion O, Tolck P, Morales M. Subacute uterine inversion: description of a novel replacement technique using the obstetric ventouse. BJOG. 2006;113:846-7

9. You W, Zahn C. Postpartum hemorrhage: abnormally adherent placenta, uterine inversion, and puerperal hematomas. Clin Obstet Gynecol. 2006;49:184

10. Adesiyun A. Septic postpartum uterine inversion. Singapore Med J. 2007;48:943. 